\title{
Letters
}

\section{Removal of complement factor $D$ by adsorption on polymethylmethacrylate dialysis membranes}

Sir,

Factor $D$ is the rate-limiting enzyme of the alternative pathway of complement activation [1]. Similarly to many other small-molecular-weight proteins, factor $\mathrm{D}$ accumulates in renal failure. The mean concentration of factor $D$ is $1.8 \mu \mathrm{g} / \mathrm{ml}$ in normal individuals and approximately 10 -fold higher in patients with end-stage renal failure undergoing haemodialysis [2]. This increased level of functionally active factor $D$ is responsible for enhanced activation of the alternative pathway in the plasma of patients with end-stage renal failure [3]. This situation is particularly unfavourable if one considers that the blood of such patients is repeatedly exposed to artificial membranes. Indeed, most dialysis membranes trigger complement activation by the alternative pathway. Because of its size $(24 \mathrm{kDa})$, factor $\mathrm{D}$ is unlikely to be cleared efficiently during haemodialysis even by highly permeable filters. Some dialysis membranes have, however, the capacity to adsorb proteins. For example, $\beta_{2}$-microglobulin $(12 \mathrm{kDa})$ is cleared from plasma by adsorption to dialysis filters made of polyacrylonitrile or polymethylmethacrylate (PMMA) membranes $[4,5]$.

We investigated whether factor D is adsorbed on PMMA, in vitro and in vivo. In vitro, normal human serum was exposed to various quantities of PMMA-BK-P (pores of 6-8 nm), PMMA-B2 ${ }^{\circledR}$ (pores of $1.5-2 \mathrm{~nm}$ ) or cuprophane fibres obtained by cutting small fragments of new hollowfibre dialysers. Residual haemolytic factor $\mathrm{D}$ was measured after an incubation of $30 \mathrm{~min}$ at $37^{\circ} \mathrm{C}[6]$. There was a loss of haemolytic factor $D$ in normal serum exposed to PMMABK-P. whereas no loss was observed with the other fibres. This loss was dose-dependent and reached $81 \%$ when $75 \mu \mathrm{l}$ of serum were incubated with $40 \mathrm{mg}$ of fibres. Removal of factor $\mathrm{D}$ was then monitored in vivo during seven dialysis sessions of patients on chronic haemodialysis using PMMABK-1.6 $\mathrm{P}^{\mathbb{B}}$ filters.

The factor D levels (corrected for haemoconcentration) decreased from $24.1 \pm 7.4 \mu \mathrm{g} / \mathrm{ml}$ to $12.2 \pm 3.5 \mu \mathrm{g} / \mathrm{ml}$ $(P<0.005$, paired $t$ test) at the end of dialysis (Figure 1), whereas only a small decrease (from $25.1 \pm 3.1 \mu \mathrm{g} / \mathrm{ml}$ to $22.7 \pm 2.6 \mu \mathrm{g} / \mathrm{ml}, P<0.05)$ was observed during five dialysis sessions with cellulose acetate filters (controls, not shown). The decrease of factor $\mathrm{D}$ levels was progressive during dialysis, and in the same range as that of $\beta_{2}$-microglobulin (respectively $49.4 \pm 6.6 \%$ and $41.2 \pm 6.7 \%$ ). The total amount of factor $D$ removed per dialysis was calculated to be approximately $60 \mathrm{mg}[6]$. Some loss of factor D occurred by mass transfer of the protein to the dialysate, since $9 \pm 2 \mathrm{mg}$ were recovered in the dialysate from three patients. A similar mass transfer of factor $D$ was observed when cellulose acetate filters were used. Thus, most of factor D removal by PMMABK-P was due to adsorption. This adsorption seems to be maximal at the beginning of the dialysis session, since samples of dialysis fluid taken 5 min after the start of dialysis contained no factor $D$, whereas those taken at $30 \mathrm{~min}$ were positive.

Because of its short half-life, factor $D$ levels in plasma are rapidly reconstituted after the end of dialysis. The transient

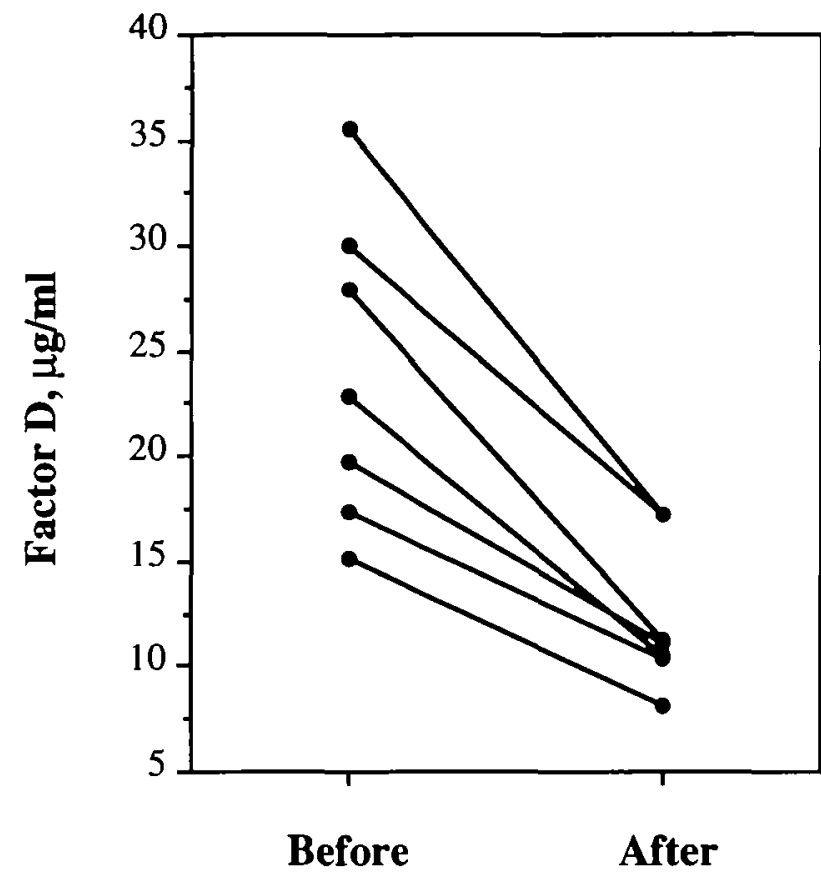

Fig. 1. Plasma levels of complement factor $D$ before and after dialysis of patients with PMMA-BK-P filters.

decrease of factor D might, however, have a favourable effect by decreasing alternative pathway activation during haemodialysis. Furthermore, a sustained reduction in factor D levels might be obtained during continuous haemofiltration as performed in patients with acute renal failure due to sepsis or other causes. Under such circumstances, a partial decrease in the activation of the alternative pathway might favourably affect the outcome of the patient [7]. Other biomaterials adsorb factor $D[8,9]$. It appears certainly worthwhile to develop new biomaterials that down-regulate complement activation during dialysis.

Laboratory of Immunonephrology, Centre Médical Universitaire, Geneva, Switzerland

Division of Nephrology, CHUV, Lausanne, Switzerland

1. Lesavre PH, Maller-Eberhard HJ. Mechanism of action of factor D of the alternative complement pathway. $J$ Exp Med 1978; 148: 1498-1509

2. Volanakıs JE, Barnum SR, Giddens M, Galla JH. Renal filtration and catabolism of complement protein D. $N$ Engl J Med 1985; 312: 395-399

3. Pascual M, Paccaud JP, Macon K, Volanakis JE, Schifferli JA. Complement activation by the alternative pathway is modified in renal failure: the role of factor D. Clin Nephrol 1989; 32: 185-193

4. Goldman $M$, Dhaene $M$, Vanherweghem JL. Removal of $\beta_{2}$. microglobulin by adsorption on dialysis membranes. Nephrol Dial Transplant 1987; 2: 576-577

5. Mineshima $\mathrm{M}$, Hoshino $\mathrm{T}$, Era $\mathrm{K}$ et al. Difference in beta-2-microglobulin removal between cellulosic and synthetic polymer membrane dialyzers. ASAIO Trans 1990; 36: M643-646 6. Pascual M, Steiger G, Estreicher J, Macon K, Volanakis JE, 
Schifferli JA. Metabolism of complement factor D in renal failure. Kidney Int 1988; 34: 529-536

7. Hakim RM, Wingard RL, Lawrence P, Parker A, Schulman G. Use of biocompatible membranes improves outcome and recovery from acute renal failure. $J A S N$ 1992; 3: 367

8. Pascual M, Schifferli JA. Adsorption of complement factor D by polyacrylonitrile dialysıs membranes. Kidney Int 1993; 903-911

9. Pascual M, Plastre O, Montdargent B, Labarre D, Schifferli JA. Specific interactions of polystyrene biomaterials with factor $D$ of human complement. Biomaterials 1993; 14: 665-670

\section{OKT3: a therapeutic alternative in recurrence of focal glomerulosclerosis in the transplanted kidney?}

Sir,

The longer survival in renal transplants due to better immunosuppression has increased interest in recurrence of primary nephropathies in the graft. In childhood the incidence of post-transplant recurrence of focal segmental glomerulosclerosis ranges from 15 to $40 \%$, according to the series $[1,2]$. Once the recurrence is diagnosed the deterioration of the graft is usually rapid, resulting in graft loss. We report a girl with steroid-resistant nephrotic syndrome due to focal segmental glomerulosclerosis and its outcome after three consecutive renal transplants.

A female, 2 years 5 months, who presented with a nephrotic syndrome resistant to 8 weeks of standard treatment with prednisone and to one cyclophosphamide course of 8 weeks is described. The renal biopsy showed a focal segmental glomerulosclerosis with mesangial proliferation. The condition progressed to end-stage renal disease 20 months after onset of the disease. In June 1983 she received a renal graft from a live related donor, and a bilateral nephrectomy was performed at the same time. Conventional immunosuppression with prednisone, beginning with $3 \mathrm{mg} / \mathrm{kg}$ per day and tapering to $0.2 \mathrm{mg} / \mathrm{kg}$ per day by 6 months posttransplantation, and azathioprine $(2 \mathrm{mg} / \mathrm{kg}$ per day) was followed. She showed an immediate recurrence with proteinuria $>40 \mathrm{mg} / \mathrm{m}^{2}$ per hour and hypoalbuminaemia of $2.2 \mathrm{~g} / \mathrm{dl}$. A biopsy of the allograft carried out 6 months later showed focal segmental glomerulosclerosis with mesangial proliferation, as in the native kidney. Nephrotic syndrome status was maintained during the entire post-transplant follow-up, until the reinstitution of dialysis therapy after 11 months.

In April 1985 the patient received a second renal graft from a cadaver donor. The immunosuppression schedule included prednisone and cyclosporin $(5-7 \mathrm{mg} / \mathrm{kg}$ per day) from the first day. After the fifth transplant day, a massive proteinuria $>40 \mathrm{mg} / \mathrm{m}^{2}$ per hour and hypoalbuminaemia $<2.5 \mathrm{~g} / \mathrm{dl}$ appeared. The hypoalbuminaemia was corrected after 5 months, keeping the proteinuria between 60 and $80 \mathrm{mg} / \mathrm{m}^{2}$ per hour. This time the progressive reduction of allograft function was slower and led to reinstitution of dialysis therapy after 44 months. No episode of rejection was diagnosed. Histological confirmation of recurrence was made on the allograft nephrectomy.

In March 1991 the patient received a third renal graft from a cadaver donor. This time the immunosuppression schedule included OKT3 at $5 \mathrm{mg} /$ day as induction therapy, beginning at the surgery room and maintained until cyclosporin addition at the 5th day. Immediate diuresis was established but a similar clinicobiochemical nephrotic syndrome developed again within the $12-48 \mathrm{~h}$ following surgery. A complete remission of the nephrotic syndrome was achieved after the fourth day of OKT3 therapy. Currently, after 24 months of follow-up, the patient has not had any further proteinuria, keeping steady creatinine levels of $88 \mu \mathrm{mol} / 1$. She remains immunosuppressed with cyclosporin and prednisone.

The patient showed all the criteria for poor transplant outcome because of high risk of recurrence: (1) age less than 3 years at the onset of the disease; (2) rapid evolution to end-stage renal disease; (3) mesangial proliferation in the renal biopsy; and (4) steroid-resistant nephrotic syndrome. The immediate evolution in the three consecutive renal grafts was characterized by the rapid reappearance of nephrotic syndrome. The course of the second graft, treated with cyclosporin, was characterized by a partial remission of the nephrotic syndrome and a slower deterioration of the renal function. The cyclosporin effect suppressing $T$ lymphocyte response through the reduction of lymphokine secretion seems to be the key to its therapeutic action in the nephrotic syndrome $[3,4]$. The resolution of the nephrotic syndrome in the third transplant may be due to a similar effect of OKT3 therapy on T lymphocyte function.

Paediatric Nephrology Unit

Hospital Infantil LA FE

Av Campanar, 21

Valencia, Spain

1. Senguttuvan P, Cameron JS, Hartley RB et al. Recurrence of focal segmental glomerulosclerosis in transplanted kidney; analysis of incidence and risk factors in 59 allografts. Pediatr Nephrol 1990; 4: $21-28$

2. Cameron JS. Recurrent primary disease and de novo nephritis following renal transplantation. Pediatr Nephrol 1991; 5: 412-421

3. Striegel JE, Sibley R K, Fryd DS, Mauer SM. Recurrence of focal segmental sclerosis in children following renal transplantation. Kidney Int 1986; 30: S44-S50

4. Burke JR, Rigby RJ. Cyclosporin and prednisolone: do they prevent recurrence of focal segmental glomerulosclerosis? Nephron 1986; 43: 236-237

\section{Haemorrhagic fever with renal syndrome}

Sir,

Haemorrhagic fever with renal syndrome (HFRS) is caused by Hantavirus infection. This virus is thought to be distributed world-wide, primarily in rodent reservoirs. HFRS is characterized by fever, hypotension purpura, and interstitial nephritis [1]. It has now been identified in many countries in Europe and in the United States of America, areas not previously thought to be endemic for these viruses. Davies et al. [2] have provided presumptive evidence for the presence of Hantavirus in Ireland. Although the acute disease appears to resolve, there is now increasing evidence that residual renal dysfunction and perhaps progression to chronic renal failure can ensue. In this regard, $9 \%$ ( 8 of 90$)$ patients on chronic renal dialysis in Northern Ireland and 2.7\% (7 of 254) of chronic dialysis patients in Baltimore, Maryland, USA were found to have serologic evidence of exposure to Hantavirus $[3,4]$.

We screened blood samples from 411 renal patients in the republic of Ireland, of whom 203 were on maintenance haemodialysis and 207 had a functioning renal transplant. Patients were studied from all the renal units in Ireland and thus had both rural and urban distribution. All sera were screened at 1 in 100 dilutions for IgG antibodies to protype Hantaan virus by ELISA. Antigen was derived from Vero-E 6 infected cell lysates. 